\title{
Venturi Multiphase Flow Measurement based Active Slug Control
}

\author{
Somtochukwu Godfrey Nnabuife ${ }^{1}$, James Whidborne ${ }^{2}$, Liyun $\mathrm{Lao}^{1}$, Yi Cao ${ }^{3}$ \\ ${ }^{1}$ School of Water, Energy, and Environment, Cranfield University, Cranfield, United Kingdom \\ ${ }^{2}$ School of Aerospace, Transport, and Manufacturing, Cranfield University, Cranfield, United Kingdom \\ ${ }^{3}$ College of Chemical and Biological Engineering, Zhejiang University, People's Republic of China \\ *Corresponding author, email address: j.f.whidborne@cranfield.ac.uk
}

\begin{abstract}
Riser slug flow poses a significant challenge to offshore oil production systems, most especially for oil fields in their later life. Active control of slugging through choking has been proven a practical approach in eliminating riser slug flow in oil production pipeline-riser systems. However, existing conventional active slug control systems may reduce oil production significantly due to excessive over choking. Again, some of the existing active slug flow control systems rely on seabed measurements, which are difficult to maintain, costly to install, unreliable, and seldom readily available. This study is an experimental investigation of the feasibility of active riser slug control by taking topside differential pressure measurement from the inlet of the venturi flow meter to the throat. Experimental results indicate that under active slug flow control, the system was able to eliminate slug flow at a higher valve opening when compared to manual choking. A valve opening of $24 \%$ with riser base pressure at 2.85 bar from open loop unstable of $23 \%$ was recorded, which is superior to manual choking which maintained flow stability up to $21 \%$ valve opening with riser base pressure of $3.8 \mathrm{bar}$.
\end{abstract}

Keywords- Riser slug flow, Pipeline-riser system, Differential pressure, Venturi flow meter, Choking, Active slug control. Introduction

\section{INTRODUCTION}

One of the most challenging flow regimes in riser pipeline systems is riser-induced severe slug flow because it can cause riser-pipeline system instability. During the later life of oil field production when reservoir pressure and production are low, riser-induced severe slug flows form in the pipeline-riser system because of low liquid and gas flow rates. Riser-induced severe slug flow consists of four cyclic processes which include the liquid slug buildup/formation, slugging production, gas infiltration and gas blowout/liquid fallback [1], [2].

This transient four cycle process causes large fluctuations in pressure and flow rate of the system, creating problems in downstream facilities such as compressors, pumps, and separators, designed to operate under stable operating conditions.

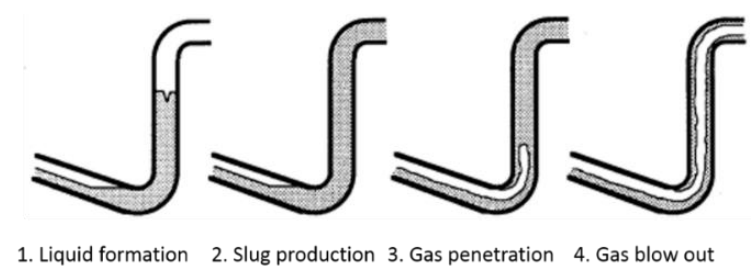

Figure 1: Cycles of riser-induced severe slug flow [3].

Riser-induced severe slug flow is an undesirable flow regime and has caused several operational problems such as:

- Overpressurisation of the separator: The maximum flow rates during gas and liquid upsurge might induce flooding and separator overpressurisation, which may lead to complete plant shutdown [4].

- Increased back pressure: Increased back pressure at the wellhead may cause production termination and well abandonment [4]. 
- Uneven flow: high liquid flow, followed by a large volume of gas delivery and then a period of no-flow. The result is unnecessary gas flaring, high-level trips and overpressurisation in the separator [5].

- Increased mechanical stresses: High liquid flow velocities during blowdown periods and a highly varying liquid inventory in the riser cause stress and decrease the riser operating life [6], [5].

Riser-induced severe slug flow could be problematic in oil production systems offshore especially for oil fields in their later life. Considering different slug flow elimination methods proposed in the literature, active slug flow control has numerous benefits; it is less expensive than the implementation of new equipment, it requires less modification to the existing production systems, and also it eliminates slug thereby eliminating strain on the system. Hence there can be considerable financial savings on system maintenance.

The first application of active slug flow control can be found in the Ph.D. work of Schmidt in the 1970s, where severe slug flow was eliminated by choking the riser outlet flow. However, choking the riser outlet increases the backpressure, which reduces overall oil production. However, Jansen et al [7] report that using an automatic control valve at the riser outlet to regulate (control) the pressure at the riser base would reduce the backpressure needed to eliminate slug flow instead of choking the riser outlet flow manually. In reference to this principle, ASEA Brown Boveri (ABB) developed an active slug controller using upstream riser pressure as the measurement [8], [9].

The control solution in Havre et al [8] and Havre and Dalsmo [9] requires riser base pressure measurement, which is difficult to maintain, unreliable and expensive. However, to avoid the use of riser base pressure, an idea was proposed to maintain outlet riser flow at the steady condition to reduce the fluctuation induced by slug flow. To facilitate the multiphase flow measurement at the outlet riser, a small pre-separator was introduced between the first stage separator and the riser to provide both liquid and gas flow rates. This resulted in the development of Shell's Slug Suppression System $\left(S^{3}\right)$ [10] and Shell's Vessel-less $S^{3}$ system [11]. The major disadvantage of this control solution is that it requires retrofit of the existing system for new devices installation.

While the $S^{3}$ and the Vessel-less $S^{3}$ are robust solutions for controlling gas surges and mitigating liquid slugs, they require the pre-separation of liquid and gas phases in each pipeline where slug flow could be a problem. The system requires two control valves which in combination with the separator may not be cost effective for some slug flow problems that only appear in a field's later life. Again, for some situations where multiple risers/pipelines have to be onboarded to a single production facility, the $S^{3}$ is not a feasible option. A slug flow mitigation solution based on a single valve that can effectively control gas surges and mitigate liquid slugs is then a preferred option. Based on this principle, the Shell Smart Choke was developed, where the $S^{3}$ control algorithm is implemented on a single control valve. However, this solution was also based on controlling the flow rates [12], [13]. Some other contributions on active slug flow control can be found, e.g. [14], [15], [16], [17], [18], [19].

In brief, the major contribution of the present paper is to investigate the feasibility of active slug control by taking the differential pressure measurement from the venturi inlet to the throat.

The remainder of the paper is structured as follows. Section II presents the experimental setup for the work. In Section III, the discussion and results are presented, and finally, the conclusion is presented in Section IV.

\section{EXPERIMENTAL SETUP}

\section{A. The Multiphase Flow Facility}

The Oil and Gas Centre at Cranfield University has a near industrial-scale multiphase flow test facility that is one of the best in the United Kingdom. It is a fully-automated facility with a modern industrial standard distributed control system; this being a Fieldbus-based supervisory, control and data acquisition system, the DeltaV produced by Emerson Process Management group. A schematic of the rig is shown in Figure 3.

The multiphase flow facility is a completely computerized high-pressure test rig structured to control and meter the flow rate of gas-liquid mixtures in the fluid metering section of the facility into the test section and then the separation section where the gas-liquid mixtures are further separated into their individual phases. The oil and water are cleaned in their respective coalescers after the final separation in the horizontal three-phase gravity separator before being returned to the repository vessel and the air is released into the atmosphere. A bank of two blowers/compressors supply the air. A peak air flow rate of $1410 \mathrm{~m}^{3} / \mathrm{hr}$ Free Air Delivery (FAD) at seven bars can be supplied if the compessors are arranged in parallel [20]. An $8 \mathrm{~m}^{3}$ capacity receiver accumulates the air in order to maintain a constant pressure of the air from the compressors. After the receiver, the air flows through a bank of three filters (medium, coarse, fine) followed by a cooler so that condensates and debris are removed prior to entering the flow meters [20]. The water is provided from a water tank with $12.5 \mathrm{~m}^{3}$ capacity. Two multistage Grundfos CR90-5 pumps supply the water into the flow loop. Each pump has a duty of $100 \mathrm{~m}^{3} / \mathrm{hr}$ at 10 bars and speed control is actuated by using frequency variables inverters. The water pumps are controlled remotely using the DeltaV SACDA system. The water flow rate is measured using a 1-inch Rosemount 8742 magnetic flow meter (up to 7.36 1/s) and 3-inch Foxboro CFT50 Coriolis meter (up to 30kg/s) [20]. 
Following the experiment, the water and air are separated in an $11.12 \mathrm{~m}^{3}$ horizontal multiphase gravity separator. After separating and cleaning, the air is emitted into the atmosphere while water enters a $1.6 \mathrm{~m}^{3}$ coalescer where additionally cleaning takes place before being returned to the storage tank [20]. A schemetic of the venturi flow meter is presented in Figure 2.

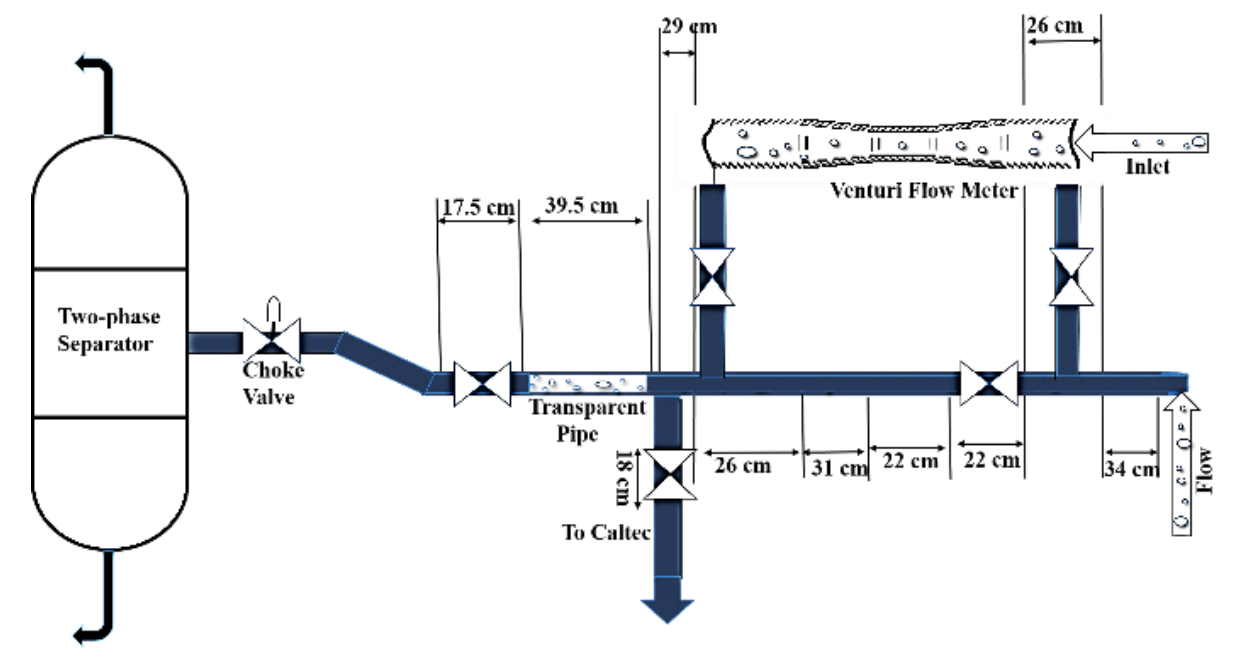

Figure 2: Schematic of the flow facility section showing the venturi meter

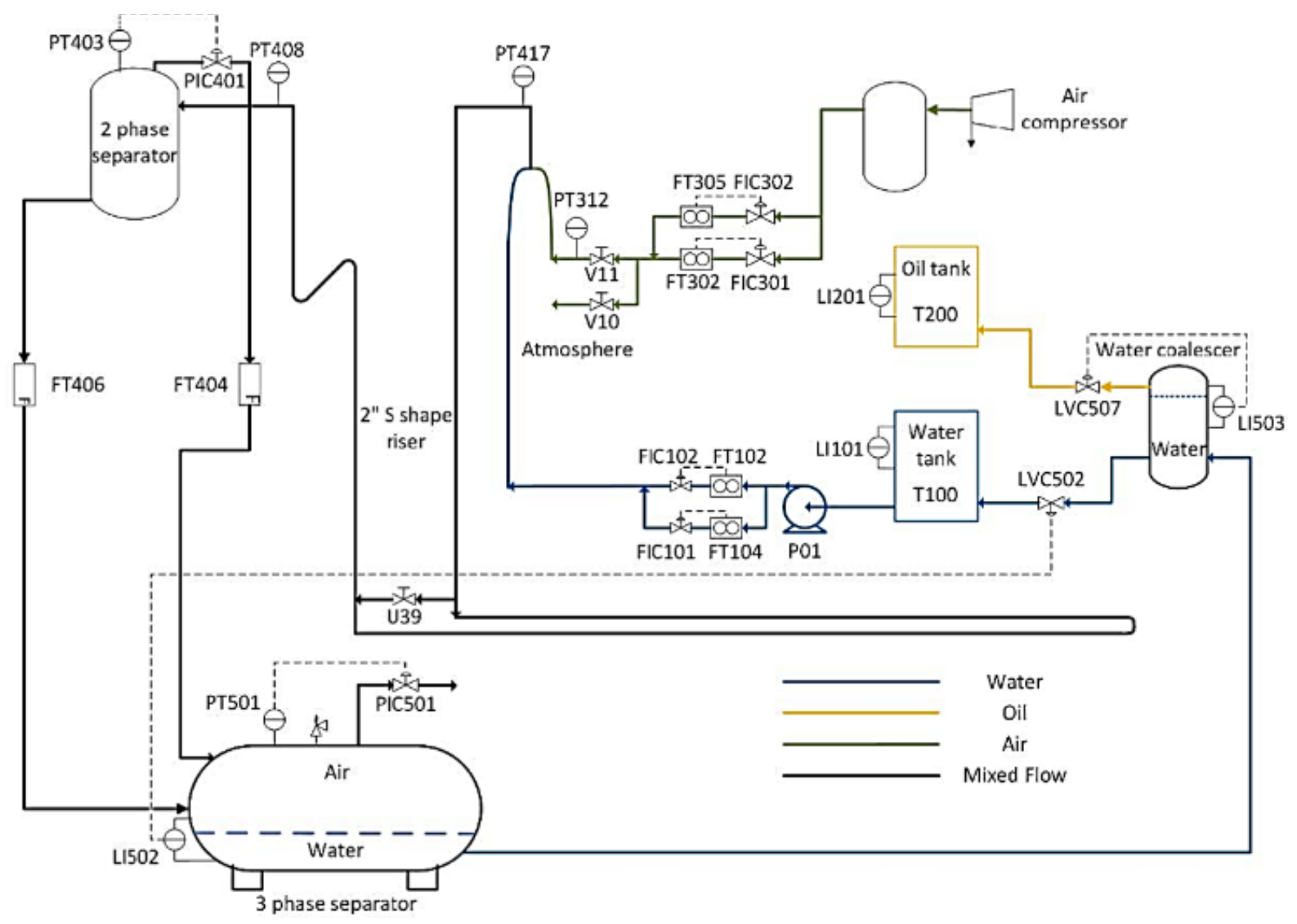

Figure 3: Schematic diagram of the multiphase flow test facility 
Table 1: Experimental process and instrumentation list

\begin{tabular}{lll}
\hline $\begin{array}{l}\text { Sensor } \\
\text { tags }\end{array}$ & Description & Unit \\
\hline DPT409 & $\begin{array}{l}\text { Differential pressure } \\
\text { (Venturi inlet-throat) }\end{array}$ & bar \\
PT312 & Air delivery pressure & bar \\
PT403 & Top separator pressure & bar \\
PT408 & Riser top pressure & bar \\
PT417 & Riser base pressure & bar \\
PT501 & 3-phase separator pressure & $\mathrm{bar}$ \\
PIC501 & 3-phase separator outlet air & $\%$ \\
& valve & \\
FT102 & Inlet water temperature & ${ }^{\circ} \mathrm{C}$ \\
FT102 & Inlet water density & $\mathrm{Kg} / \mathrm{m}$ \\
& Inlet water flow rate & $\mathrm{Kg} / \mathrm{s}$ \\
FT102/104 & Air temperature (inlet) & ${ }^{\circ} \mathrm{C}$ \\
FT305 & Air flow rate (inlet) & $\mathrm{Sm} / \mathrm{h}$ \\
FT305/302 & $\mathrm{r}$ & \\
& & $\mathrm{M}^{3} / \mathrm{hr}$ \\
FT404 & Top separator gas outlet & $\mathrm{Kg} / \mathrm{s}$ \\
FT406 & Top separator liquid outlet & $\mathrm{m}$ \\
LI101 & Liquid tank level & $\%$ \\
LI502 & Three-phase separator & $\%$ \\
LI503 & water-oil level & \\
LVC502- & Outer valve liquid coalescer & $\%$ \\
SR & level & \\
\hline
\end{tabular}

\section{B. The S-shape Riser Test Section}

The riser test section where the experiment is carried out consists of a 2 -inch S-shaped riser comprising a $3.5 \mathrm{~m}$ topside section, a $5.7 \mathrm{~m}$ vertical upper section, a $5.5 \mathrm{~m}$ vertical lower section, a $1.5 \mathrm{~m}$ down-comer, and a $40 \mathrm{~m}$ horizontal pipeline. The S-shaped 2-inch pipe is transparent to allow observation of the different flow regimes. The desired flow regime is obtained by control of the flow rate is by adjusting the the valves via the DeltaV SCADA [20].

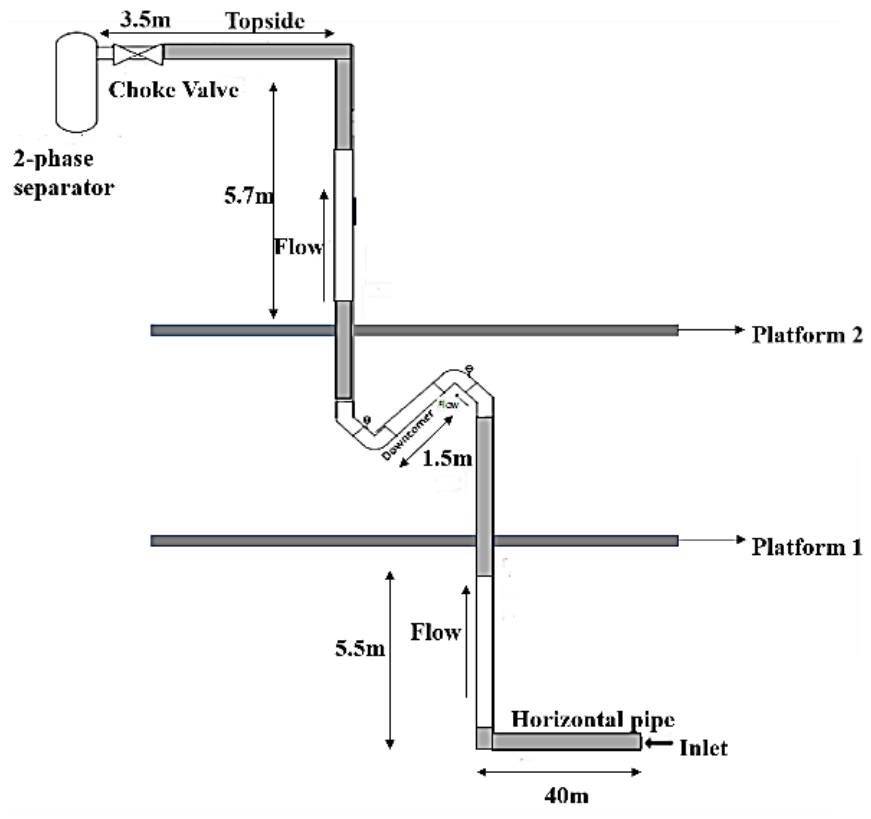

Figure 4: Schematic diagram of the S-shape rig 


\section{RESULTS AND DISCUSSIONS}

\section{A. Flow Regime}

Flow regime maps are vital tools for obtaining an overview of the flow patterns that can be expected for a particular fluid condition. These maps depict the geometrical distribution of the flow moving through a pipeline. Different flow regimes such as bubbly, slug, churn and annular are used to depict this distribution [20]. Two-phase flow regimes have often been illustrated as maps, or plots, with the superficial phase velocities on each axis.

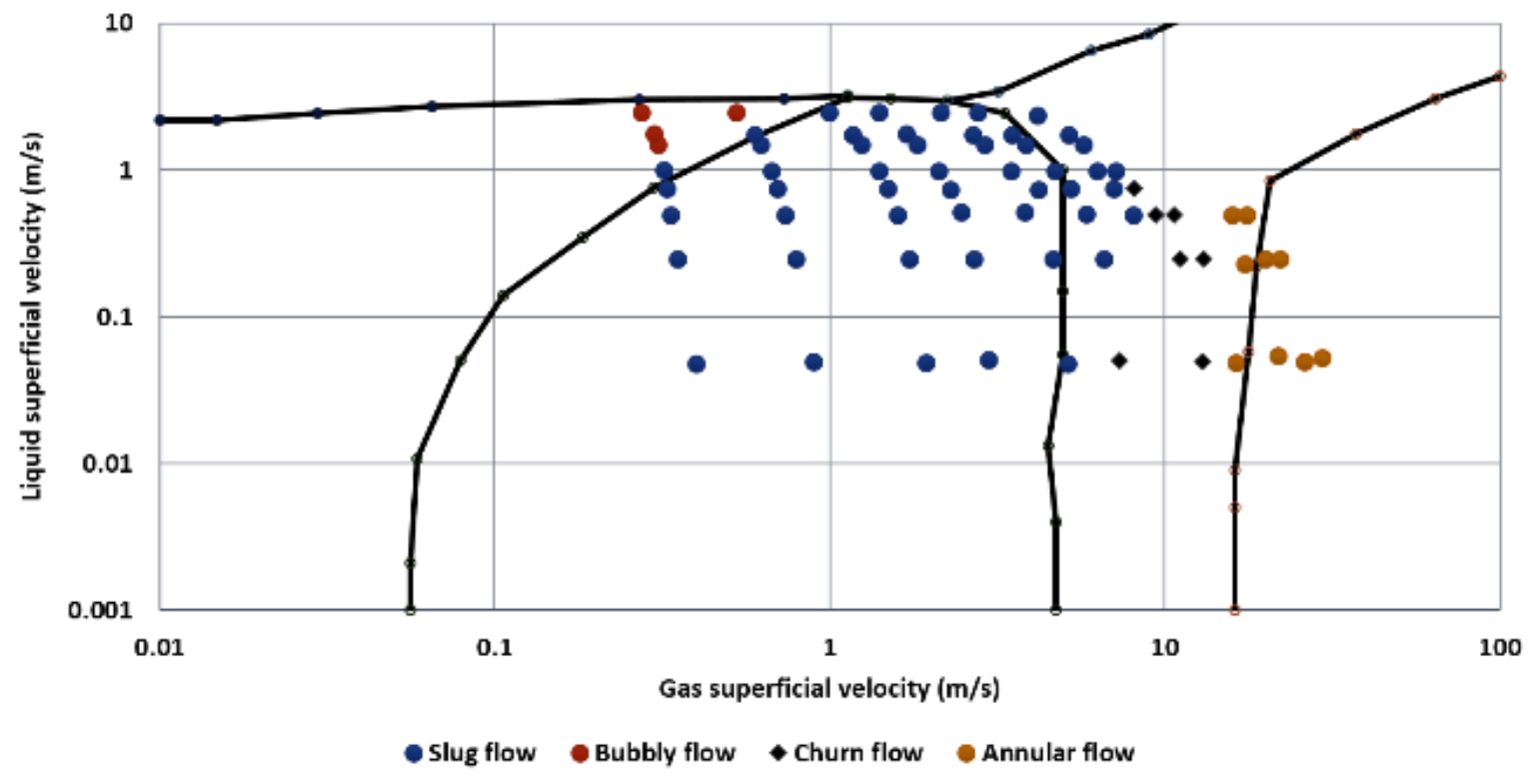

Figure 5: Experimental flow regime map for the 2-inch S-shaped riser with venturi

The flow regime map was examined to estimate the operating conditions under severe slugging conditions. The selected operating points that fall into the slugging regime are the gas flow rate of $10 \mathrm{Sm}^{3} / \mathrm{h}$ and liquid flow rate of $1 \mathrm{~kg} / \mathrm{s}$ with the gas superficial velocities being $0.6941 \mathrm{~m} / \mathrm{s}$ and $0.4952 \mathrm{~m} / \mathrm{s}$, respectively.

\section{B. S-shape riser pressure trend}

At the flow condition of $10 \mathrm{Sm}^{3} / \mathrm{h}$ and liquid flow rate of $1 \mathrm{~kg} / \mathrm{s}$ with superficial velocities of $0.6941 \mathrm{~m} / \mathrm{s}$ and 0.4952 $\mathrm{m} / \mathrm{s}$, respectively, a severe slug flow was observed as illustrated in Figure 6. At this flow condition, the maximum and minimum pressure was 1.89 barg and 1.49 barg respectively. Hence, the magnitude of oscillation is 0.40 barg. The period of oscillation which is the time taken to complete one full oscillation or cycle was observed to be 20 seconds. All these observations indicated that the system is under severe slugging.

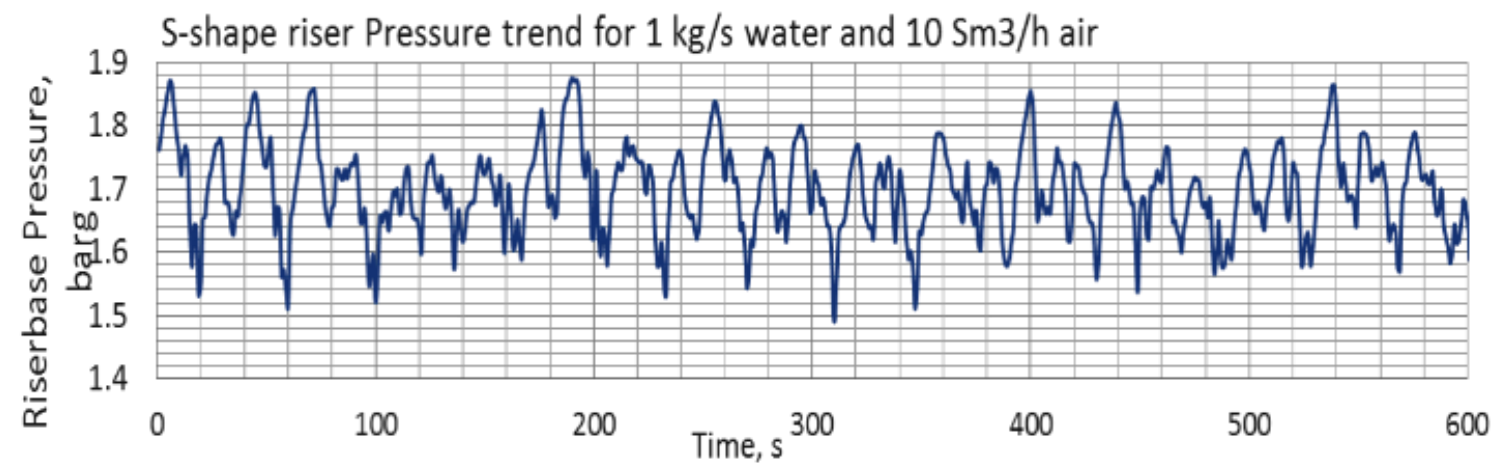

Figure 6: S-shape riser pressure trend for $1 \mathrm{~kg} / \mathrm{s}$ water and $10 \mathrm{Sm} 3 / \mathrm{h}$ air 


\section{System Stability (Bifurcation map)}

Bifurcation map assessment is an investigation of system stability at a constant flow rate. A bifurcation can be obtained by keeping the flow rate constant and varying the valve openings $(1 \%-100 \%)$. This investigation aims to identify the bifurcation point which is the most extreme valve opening at which the pipeline flow system becomes stable in open loop. This equates to the point at which the pipeline system becomes unstable due to an increase in the valve opening [14]. Analytically, this is equivalent to a pair of complex poles crossing over the imaginary axis of the complex s-plane, the Hopf bifurcation whereby stability is lost and seld-sustained oscillation or limit cycles may result. In designing the controller, the initial stage is to identify the system bifurcation point, that is, the highest valve opening for which the flow becomes steady in an open-loop flow condition [14]. This gives the reference point for the active slug controller to stabilize the flow in an open-loop unstable region as illustrated in Figure 7.

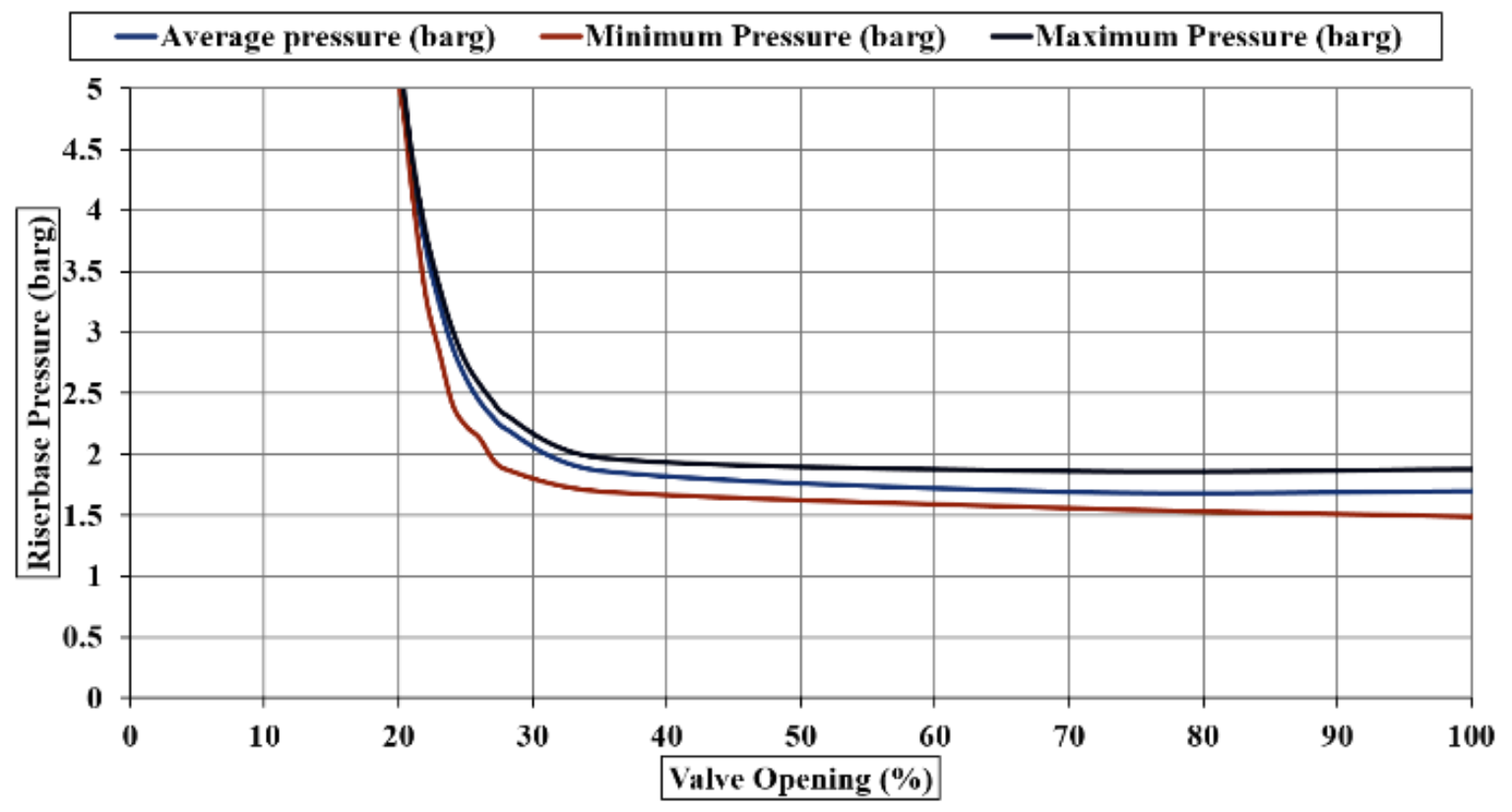

Figure 7: Bifurcation Map of $1 \mathrm{~kg} / \mathrm{s}$ of Water and $10 \mathrm{Sm} 3 / \mathrm{h}$ of Air

Figure 7 shows the bifurcation point for the boundary condition of the 2-inch S-shaped riser, where system stability was obtained at a valve opening of $21 \%$, which corresponds to a pressure of 3.8 bars from the result of the bifurcation map. This is the highest choke valve opening for stable operations when no active slug control is applied, stabilising the system at the open-loop unstable region where $u>21 \%$ will be aimed for to obtain a desired stable non-oscillatory flow regime.

\section{Slug control using differential pressure from the venturi inlet to the venturi throat}

Figure 8 demonstrates that slug flow stability using differential pressure from the venturi inlet to the venturi throat stabilised the flow from a valve opening of $23 \%$ open-loop unstable to $24 \%$. Figure 8 a indicates that the riser system was unstable at valve opening of $23 \%$ from zero until the controller was switched on at 300 seconds, which stabilised the system. The same process happened in Figure $8 \mathrm{~b}$, but in Figure 8c, the system was unstable even when the controller was switched on. A benefit of a $4 \%$ reduction in the riser base pressure from 2.95 barg to 2.85 barg was recorded with a $14 \%$ increase in production. Hence, this demonstrates a superior control performance given that with manual choking the flow was stabilised at $21 \%$ valve opening. 


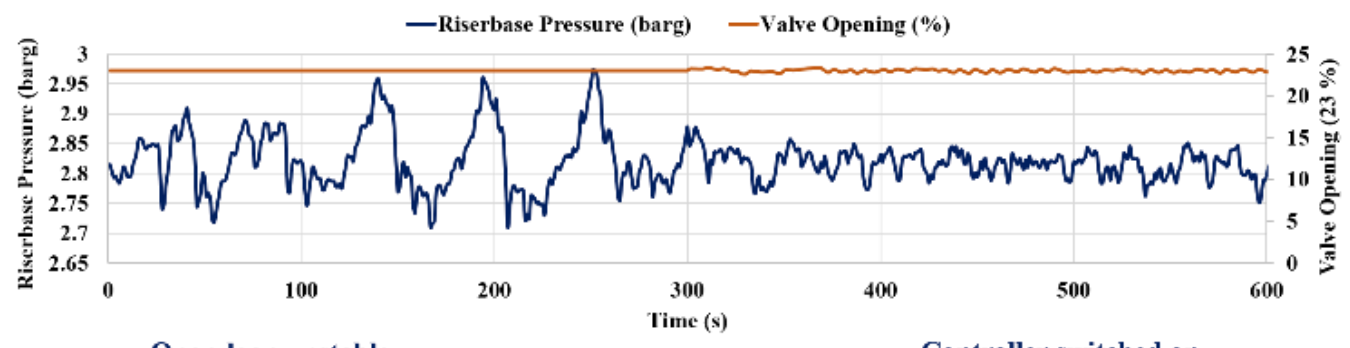

Open-loop unstable

Controller switched on
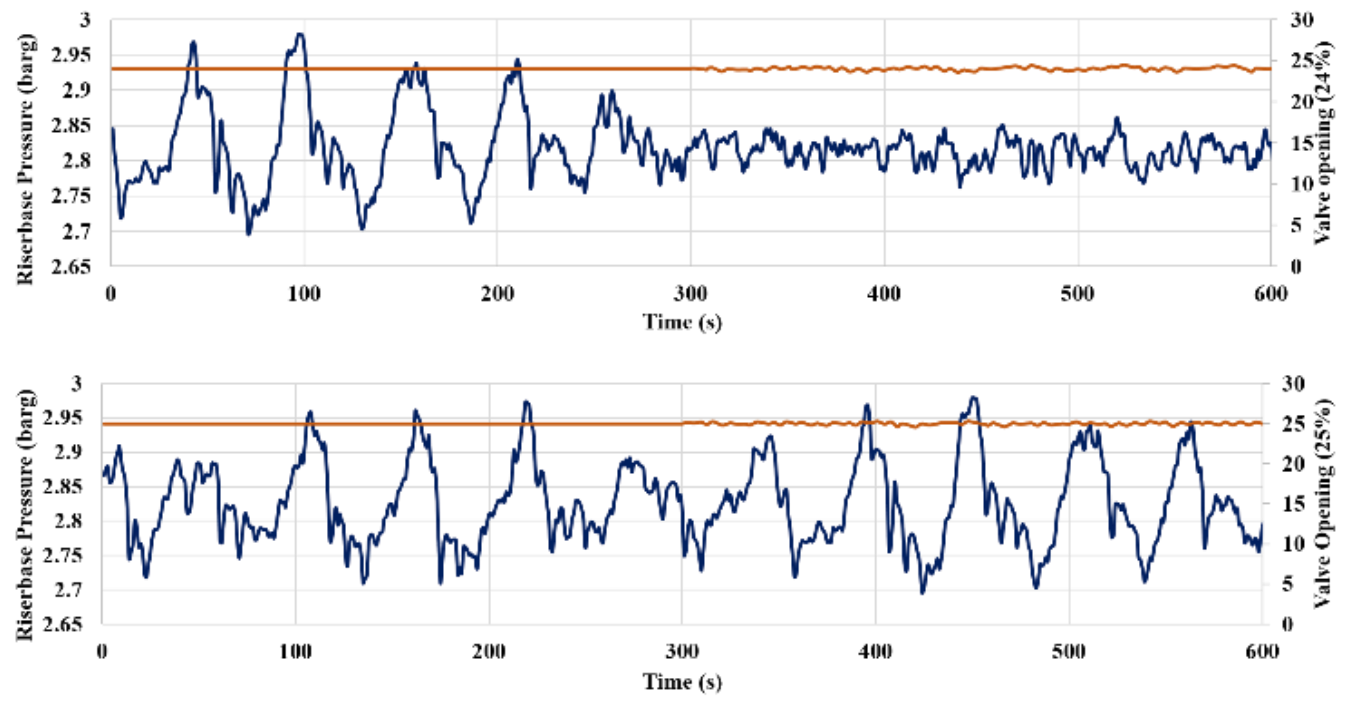

Figure 8: Riser base pressure response with the equivalent valve opening using the differential pressure measurement from the venturi inlet-throat.

\section{CONCLUSION}

An effort was made to control the riser slug flow by taking the differential pressure measurement from the venturi inlet to the throat. The controller was able to stabilise the flow with an acceptable control performance.

The experiment was successful; the flow was controlled satisfactorily far into the unstable slugging region. To mitigate the slug flow by manually choking the choke valve, it is important to operate with a valve opening of $21 \%$. However, with the active slug controller, the flow could be controlled with an average valve opening of $24 \%$, maximising oil production.

\section{ACKNOWLEDGMENT}

The authors wish to acknowledge the Cranfield University Process System Control Group for their support.

\section{REFERENCES}

[1] Z. Schmidt, J. P. Brill, and H. D. Beggs, "Experimental study of severe slugging in a two-phase-flow pipeline riser pipe system," Soc. Pet. Eng. J., vol. 20, no. 5, p. SPE-8306-PA, 1980.

[2] Y. Taitel, “Stability of severe slugging," Int. J. Multiph. Flow, vol. 12, no. 2, pp. 203-217, 1986.

[3] J. Fabre, L. L. Peresson, J. Corteville, R. Odello, and T. Bourgeois, "Severe slugging in pipeline/riser systems," SPE Prod. Eng., vol. 5, no. 03, pp. 299-305, 1990.

[4] R. Malekzadeh, R. A. W. M. Henkes, and R. F. Mudde, "Severe slugging in a long pipeline-riser system: Experiments and predictions," Int. J. Multiph. Flow, vol. 46, pp. 9-21, 2012.

[5] J. A. Montgomery and H. C. Yeung, "The stability of fluid production from a flexible riser," J. Energy Resour. Technol., vol. 124, no. 2, p. 83-89, 2002.

[6] T. Shotbolt, "Methods for the alleviation of slug flow problems and their influence on field development planning," in European Petroleum Conference, 1986, p. SPE-15891-MS.

[7] F. E. Jansen, O. Shoham, and Y. Taitel, "The elimination of severe slugging-experiment and modeling," Int. J. Multiph. Flow, vol. 22, no. 6, pp. 1055-1072, 1996. 
[8] K. Havre, K. O. Stornes, and H. Stray, "Taming slug flow in pipelines," ABB Rev., vol. 2000, no. 4, pp. 55-63, 2000.

[9] K. Havre and M. Dalsmo, “Active feedback control as a solution to severe slugging," SPE Prod. Facil., vol. 17, no. 3, pp. 138-148, 2002.

[10] K. Kovalev, A. Cruickshank, and J. Purvis, "The slug suppression system in operation," in Offshore Europe, 2003, p. SPE 84947.

[11] K. Kovalev, M. G. W. M. Seelen, and G. Haandrikman, "Vessel-Less S3: advanced solution to slugging pipelines," in SPE Asia Pacific Oil and Gas Conference and Exhibition, 2004, p. SPE-88569-MS.

[12] N. A. Eken, G. Haandrikman, and W. M. G. M. Seelen, "Method, system, controller and computer program product for controlling the flow of a multiphase fluid," Patent US20060150749A1, 2007.

[13] S. Y. Yaw, C. Y. Lee, G. Haandrikman, G. Groote, S. Asokan, and M. E. Malonzo, "Smart choke - a simple and effective slug control technology to extend field life," in International Petroleum Technology Conference, 2014, p. IPTC-17825-MS.

[14] H. Tandoh, Y. Cao, and C. Avila, "Stability of severe slug flow in U-shape riser," in 22nd International Conference on Automation and Computing, (ICAC 2016), 2016, pp. 372-377.

[15] H. Sivertsen, V. Alstad, and S. Skogestad, "Medium-scale experiments on stabilizing riser-slug flow," SPE Proj. Facil. Constr., vol. 4, no. 4, pp. 156-170, 2009.

[16] J. M. Godhavn, M. P. Fard, and P. H. Fuchs, "New slug control strategies, tuning rules and experimental results," J. Process Control, vol. 15, no. 5, pp. 547-557, 2005.

[17] V. Henriot, A. Courbot, E. Henintzé, and L. Moyeux, "Simulation of process to control severe slugging: application to the Dunbar pipeline," in SPE Annual Technical Conference and Exhibilion, 1999, no. 56461, pp. 171-179.

[18] S. Pedersen, P. Durdevic, and Z. Yang, "Review of slug detection, modeling and control techniques for offshore oil \& gas production processes," IFAC-PapersOnLine, vol. 48, no. 6, pp. 89-96, 2015.

[19] H. Sivertsen and S. Skogestad, "Cascade control experiments of riser slug flow using topside measurements," IFAC Proc. Vol., vol. 38, no. 1, pp. 129-134, 2005.

[20] S. G. Nnabuife, K. E. S. Pilario, L. Lao, Y. Cao, and M. Shafiee, "Identification of gas-liquid flow regimes using a non-intrusive doppler ultrasonic sensor and virtual flow regime maps," Flow Meas. Instrum., vol. 68, no. $101568,2019$. 
$2019-11-11$

Venturi multiphase flow measurement based active slug control

Nnabuife, Somtochukwu Godfrey

IEEE

Nnabuife SG, Whidborne J, Lao L, Cao Y. (2019) Venturi multiphase flow measurement based active slug control. In: 25th International Conference on Automation and Computing (ICAC), 5-7 September 2019, Lancaster, UK https://doi.org/10.23919/IConAC.2019.8895212

Downloaded from Cranfield Library Services E-Repository 